\title{
Lymphocytic and collagenous colitis: The emerging entity of microscopic colitis. An update on pathophysiology, diagnosis and management
}

\author{
Ayman A Abdo MD, Stefan J Urbanski MD, Paul L Beck MD PhD
}

\begin{abstract}
AA Abdo, SJ Urbanski, PL Beck. Lymphocytic and collagenous colitis: The emerging entity of microscopic colitis. An update on pathophysiology, diagnosis and management. Can J Gastroenterol 2003;17(7):425-432.
\end{abstract}

\begin{abstract}
Microscopic colitis (MC) encompasses the two morphologically distinct entities of collagenous colitis (CC) and lymphocytic colitis (LC). MC was first described less than 30 years ago but is presently recognized as a relatively common cause of chronic diarrhea in the adult population. Remarkably, up to $10 \%$ of adults who have a colonoscopy for the investigation of chronic diarrhea, and have endoscopically normal appearing mucosa, may have MC. Patients with MC generally present with chronic diarrhea, which can be associated with cramping and bloating. Endoscopic and radiological examinations are usually normal. Histological assessment reveals inflammation consisting predominantly of lymphocytic infiltration, and a thickened subepithelial collagen band is diagnostic of CC. Both LC and CC can be associated with autoimmune diseases such as celiac disease, diabetes, arthritis and thyroiditis, yet the mechanisms involved in the pathogenesis remain unclear. Emerging studies suggest that a stepwise approach be taken in the medical management of MC. This approach includes antidiarrheal agents and stopping of any offending agents; budesonide or bismuth subsalicylate; and cholestyramine or 5-acetylsalicylic acid agents. In resistant cases, oral corticosteroids and other immune modulatory therapy have been used.
\end{abstract}

Key Words: Bismuth subsalicylate; Budesonide; Cholestyramine; Collagenous colitis; Lymphocytic colitis; Microscopic colitis
La colite lymphocytaire et collagénique :

L'entité émergente de colite microscopique.

Mise à jour sur la physiopathologie, le diagnostic et la prise en charge

La colite microscopique $(\mathrm{CM})$ couvre deux entités distinctes d'un point de vue morphologique, la colite collagénique (CC) et la colite lymphocytaire (CL). La CM a été décrite pour la première fois il y a moins de 30 ans, mais elle est maintenant acceptée comme une cause relativement courante de diarrhée chronique au sein de la population adulte. Il est remarquable de constater que jusqu'à $10 \%$ des adultes qui subissent une coloscopie afin de déceler la cause d'une diarrhée chronique et dont la muqueuse semble normale à l'endoscopie pourraient souffrir de CM. D'ordinaire, les patients atteints de CM souffrent de diarrhée chronique, qui peut s'associer à des crampes et à un gonflement. Règle générale, les examens endoscopique et radiologique sont normaux. L'évaluation histologique révèle une inflammation surtout composée d'une infiltration lymphocytaire, et un épaississement de la bande de collagène sousépithéliale permet de poser un diagnostic de CC. Tant la CL que la CC peuvent s'associer à des maladies auto-immunes comme une maladie cœliaque, un diabète, de l'arthrite et une thyroïdite, mais les mécanismes participant à la pathogenèse demeurent flous. Selon des études émergentes, une démarche étapiste devrait être privilégiée dans la prise en charge de la CM. Cette démarche inclut la prise d'antidiarrhéiques et l'interruption des agents offensants, de budésonide ou de sous-salicylate de bismuth et de cholestyramine ou d'acide 5-acétylsalicylique. Dans les cas de résistance, des corticoïdes par voie orale et un traitement immunomodulaire peuvent être privilégiés.

\begin{abstract}
$\mathrm{C}$ lassically, microscopic colitis (MC) presents as chronic diarrhea in the middle aged to elderly adult population. The colonic mucosa usually appears normal endoscopically, while histological assessment reveals specific histopathological features. Independently, in 1976, both Freeman et al (1) and Lindstrom (2) reported the features of collagenous colitis (CC). They described patients with watery diarrhea who had subepithelial mucosal collagen deposition and a chronic inflammatory cell infiltrate. These results were followed by Read and colleagues (3) who, in 1980, coined the term microscopic colitis after assessing a group of patients with chronic diarrhea and endoscopically normal appearing mucosa. Histological evaluation of the colonic biopsies from these patients revealed a chronic inflammatory infiltrate consisting predominantly of mononuclear cells. The entity of lymphocytic colitis (LC) was later proposed by Lazenby et al (4) in 1989.
\end{abstract}

MC encompasses the two morphologically distinct entities of CC and LC. CC and LC are generally similar in their presentation and natural history but differ in their histological appearance. Both entities share the feature of lymphocytic infiltration of the lamina propria and epithelium, but marked thickening of the subepithelial collagen layer differentiates CC from LC. MC was initially thought to be a very rare disorder, but with recognition of both CC and LC, most endoscopists have adopted the policy of biopsying normal appearing colonic mucosa in those with diarrhea; this has led to increased recognition of $\mathrm{MC}$ as a relatively common cause of chronic diarrhea $(5,6)$.

There is some debate in the literature as to whether CC and $\mathrm{LC}$ are distinct entities, and some individuals advocate grouping both under the term MC (7). Clearly, there are patients who have longstanding LC and do not develop the thickened

Division of Gastroenterology, University of Calgary, Calgary, Alberta

Correspondence and reprints: Dr Paul L Beck, University of Calgary, Health Sciences Centre, Division of Gastroenterology,

3330 Hospital Drive NW, Calgary, Alberta T2N 4N1. Telephone 403-220-4500, fax 403-270-0995, e-mail plbeck@ucalgary.ca 
collagen band required for the diagnosis of CC. Even though the inflammatory cells present in both LC and CC appear similar, the authours believe that it is wise to continue to differentiate these two entities until more is known about the pathogenesis, natural history and response to therapy.

\section{EPIDEMIOLOGY}

European studies estimate the yearly incidence of CC to be 0.6 to 2.3 per 100,000 population with a prevalence of 10 to 15.7 per 100,000 population (8). A prevalence of 15 per 100,000 population, which is reported in elderly females in this study, is within the reported ranges of ulcerative colitis in the general population (9). The same European study estimated the incidence of $\mathrm{LC}$ to be 3.1 per 100,000 population with a prevalence 14.4 per 100,000 population (8). In an Icelandic study, the annual incidence of CC was 5.2 per 100,000 population with a mean age at diagnosis of 66.1 years, while the incidence was LC 4.0 per 100,000 population with a mean age at diagnosis of 68.7 years (10). One recent report from Ireland, which grouped all patients with classical inflammatory bowel disease (IBD) (ulcerative colitis or Crohn's disease) together with those with $\mathrm{MC}$, found that $\mathrm{MC}$ represented up to $20 \%$ of such a group (11). In a Turkish study of patients undergoing colonoscopy for investigation of chronic diarrhea, $10 \%$ of those with endoscopically normal appearing colonic mucosa were found to have MC (12). There are no epidemiological data from North America; however, one retrospective study from three tertiary care centres in Canada found 94 cases of CC from 1990 to 1997 (13). A female predominance has been described in several studies $(8,9,14)$ and this appears to be stronger in CC than LC.

$\mathrm{MC}$ classically presents in adulthood, with the peak age of onset being in the sixth to seventh decades of life $(8,9,15)$. MC is very rare in childhood, but both LC and CC have been reported in association with celiac disease and other disease states in the pediatric population (16-18). Interestingly, LC has also been described in some children with regressive autism $(19,20)$.

\section{CLINICAL FEATURES AND DISEASE ASSOCIATIONS}

The most common presenting symptom of $\mathrm{MC}$ is chronic diarrhea. Many patients with MC report nocturnal diarrhea, abdominal pain, cramping, bloating and, occasionally, weight loss, as well as nonspecific upper gastrointestinal symptoms (6). Arthralgias and other symptoms of various other autoimmunelike conditions can occur in up to $40 \%$ of those with MC (15). Celiac disease is the most commonly reported disease associated with MC. It has been estimated that approximately onethird of patients with celiac disease have histological changes that may be compatible with MC (21). MC should particularly be looked for in patients with celiac disease who are not responding to a gluten-free diet. Collagenous sprue has also been described; this is a distinct entity in which the small bowel mucosa displays features of celiac disease as well as a thickened collagen band (22).

\section{ETIOLOGY AND PATHOPHYSIOLOGY}

The mechanisms involved in the development of MC are unknown. However, the increased association of MC with specific diseases such as celiac disease, asthma, diabetes, thyroiditis and arthritis suggest the possibility of an autoimmune-type process $(15,23-27)$. Specifically, one recent study found that $40 \%$ of patients with Hashimoto's thyroiditis had histological findings consistent with LC (26). The association with an autoimmune-like process is further supported by increased perinuclear antineutrophil cytoplasmic antibodies and antinuclear antibodies in some patients with MC $(28,29)$. Interestingly, antireticulin antibodies, which are present in about $35 \%$ of patients with celiac disease, are not more commonly found in those with LC and CC (30).

An infectious etiology has also been proposed for MC because historically some patients report a preceding infectious enteropathy and fecal stream diversion can reduce the disease severity (31). Furthermore, some studies have reported a significant clinical response to antibiotics (15).

To date, there are no detailed reports describing changes in lymphocyte populations, cytokines or chemokines in MC. Clearly, there is an increase both in intraepithelial lymphocytes (IELs) and in lamina propria lymphocytes. One study reported a significant increase in all IELs, with CD8 IELs being more numerous than CD4 IELs and the majority of IELs being of $\mathrm{T}$ cell receptor $\alpha \beta$, yet there was no increase in $\gamma \delta \mathrm{T}$ cells (32). Furthermore, this study failed to show any significant differences in T cell population when LC and CC were compared. Interestingly, the colonic epithelial cells in both LC and CC abnormally express class II major histocompatibility complex human leukocyte antigen (HLA) DR antigens (32). An earlier small study reported that patients with LC had increased HLA A1 and diminished HLA A3 compared with controls and with patients with CC (33). The HLA-DQ genes that have been found to be commonly associated with celiac disease may also be involved in the pathogenesis of MC. One study found that patients with celiac disease and LC or LC alone were more likely to be HLA-DQ2- or DQ1,3-positive than control subjects (34). There is no clear evidence that MC is an inherited disease; however, because several family clusters of $\mathrm{MC}$ have been described (35-37) and there appears to be the above HLA associations, it is likely that there is a yet-tobe-described hereditary component (Table 1).

Cells other than $\mathrm{T}$ cells may play a critical role in the development of MC. Mast cells, plasma calls and fibroblasts have been noted to be increased in numbers in patients with $\mathrm{MC}$, but these changes can be variable (38). Eosinophils are markedly increased in MC (39). Specifically, in CC, colonic eosinophils were 20 times more numerous than in control patients (40). When the expression of transforming growth factor beta (TGF $\beta$ ) - a growth factor known to induce collagen deposition - was assessed, there was marked increased colonic expression of TGF $\beta$ in those with CC and the predominant cells expressing the TGF $\beta$ were eosinophils (40) (Table 1).

Increased nitric oxide (NO) has also been reported in those with CC and LC (41,42). Inducible NO synthase (iNos) appeared to be the main source of the excess $\mathrm{NO}$ production, and when inhibitors of iNos were used, there was a net decrease in fluid secretion suggesting that the overabundance of NO contributes to the diarrhea in those with CC (41). To our knowledge, there are no studies that have examined the cytokine or chemokine profiles in patients with MC. However, it would not be unexpected to find marked alterations in these mediators in view of the increase in lymphocytes and other inflammatory cells in MC (Table 1). 
TABLE1

Factors implicated in the pathogenesis of microscopic colitis (MC)

\begin{tabular}{|c|c|}
\hline Factors & Evidence \\
\hline \multirow[t]{3}{*}{ Genetic } & Differential HLA expression \\
\hline & Family clusters \\
\hline & Association with other diseases that have a strong genetic component (ie, celiac) \\
\hline \multirow[t]{3}{*}{ Infectious } & Historically, in some cases infectious enteropathy may precede MC \\
\hline & Fecal stream diversion can decrease severity of MC \\
\hline & Some are responsive to antibiotic therapy \\
\hline \multirow[t]{4}{*}{ Altered immune response } & Association with autoimmune diseases \\
\hline & Inflammatory infiltrate predominantly alpha-beta T cells \\
\hline & Increased mast cells, plasma cells, fibroblasts, eosinophils \\
\hline & Immune modulatory therapy is effective in the treatment of $\mathrm{MC}$ \\
\hline \multirow[t]{3}{*}{ Altered inflammatory mediators } & Increased PGE2 \\
\hline & Increased nitric oxide (iNos derived) \\
\hline & Increased transforming growth factor beta \\
\hline \multirow[t]{2}{*}{ Bile salts } & Increased bile salt malabsorption in MC \\
\hline & Some are responsive to bile acid binding agents \\
\hline \multirow[t]{3}{*}{ Drugs } & Increased NSAID use in some MC population studies \\
\hline & Withdrawal of NSAIDs has been associated with improved symptoms in some patients \\
\hline & One study suggested a possible association of $\mathrm{MC}$ and the use of ticlopidine and flutamide \\
\hline \multirow{6}{*}{$\begin{array}{l}\text { Factors specifically implicated in the pathogenesis } \\
\text { of diarrhea in MC }\end{array}$} & Inflammatory cell infiltrate and increased inflammatory mediators (NO, PGE2) \\
\hline & Bile salt injury \\
\hline & Decreased net $\mathrm{Na}^{+}, \mathrm{Cl}^{-}$absorption \\
\hline & Active $\mathrm{Cl}^{-}$secretion \\
\hline & Collagen band may act as a diffusion barrier \\
\hline & Downregulation of tight junctional proteins \\
\hline
\end{tabular}

HLA Human leukocyte antigen; NO Nitric oxide; NSAID Nonsteroidal anti-inflammatory drug; PGE Prostaglandin E

In a recent, well designed study by Burgel et al (43), the mechanisms of diarrhea in $\mathrm{CC}$ were further delineated. Their main findings were that a reduced net $\mathrm{Na}^{+}$and $\mathrm{Cl}^{-}$absorption was the predominant mechanism of diarrhea in CC. Furthermore, a secretory component of active $\mathrm{Cl}^{-}$secretion was also described (43). On a more mechanical note, the collagen band was found to be a significant diffusion barrier and it was hypothesized that the noted down regulation of the tight junctional proteins, occludin and claudin-4, contributed to the diarrhea via a leak flux mechanism (43). Another study (44) also reported increased active $\mathrm{Cl}^{-}$secretion in $\mathrm{CC}$ that was possibly associated with increased prostaglandin E2 production (Table 1).

The role of prostaglandins in $\mathrm{MC}$ has been a topic of interest because there is a strong association between nonsteroidal anti-inflammatory drug (NSAID) use and MC. In a case-control study by Riddell et al (45), more than $60 \%$ of those with CC had significant NSAID use compared with less than $15 \%$ in the matched controls. Other studies of CC patients have reported NSAID use in $20 \%$ to $71 \%$ of patients with some patients improving after removal of the NSAIDs (15,46-48). Other drugs including ticlopidine (LC and CC) and flutamide (LC) have also been implicated in inducing MC (14) (Table 1).

Bile salts may play a role in the pathogenesis of $\mathrm{MC}$ in that some patients develop CC following cholecystectomy, and cholestyramine has been used, with some effect, in the treatment of MC (49). In a study of 27 symptomatic patients with CC, bile salt malabsorption (using [75] selenohomocholyltaurine [SeHCAT] testing) was markedly abnormal in 12 of 27 patients (44\%) (50). Bile acid binding treatment was followed by a rapid, marked or complete improvement in 21 of 27 patients $(78 \%)$. Rapid improvement occurred in 11 of 12 patients (92\%) with bile acid malabsorption compared with 10 of 15 patients $(67 \%)$ with normal (75)SeHCAT tests (50) (Table 1). Other previous studies have reported a lower incidence of bile acid malabsorption and a wide range in success with cholestyramine $(15,51,52)$. No randomized controlled trials have been done to assess cholestyramine in MC.

\section{DIAGNOSIS}

A detailed history, with a thorough drug history, should be the first step in evaluating a patient suspected of having MC. The diarrhea of $\mathrm{MC}$ is often chronic but may be intermittent, and it is usually described as watery. Rarely, steatorrhea has been described in those with $\mathrm{MC}$ and may be more common in those with associated celiac disease (53). Bloody diarrhea does not classically occur in MC but it has been described (53-55). Features that suggest celiac disease or IBD should be asked about, and associated autoimmune diseases should be identified. Other causes of chronic diarrhea such as infections, IBD, neuroendocrine causes and diarrhea associated with drug and/or food additive ingestion must be ruled out. In general, radiological investigations, including barium studies, are not useful in these patients but colonic dilation and a granular appearance can occasionally be seen on barium studies. In short, biopsying the colonic mucosa is the only way to make the diagnosis of $\mathrm{MC}$. 


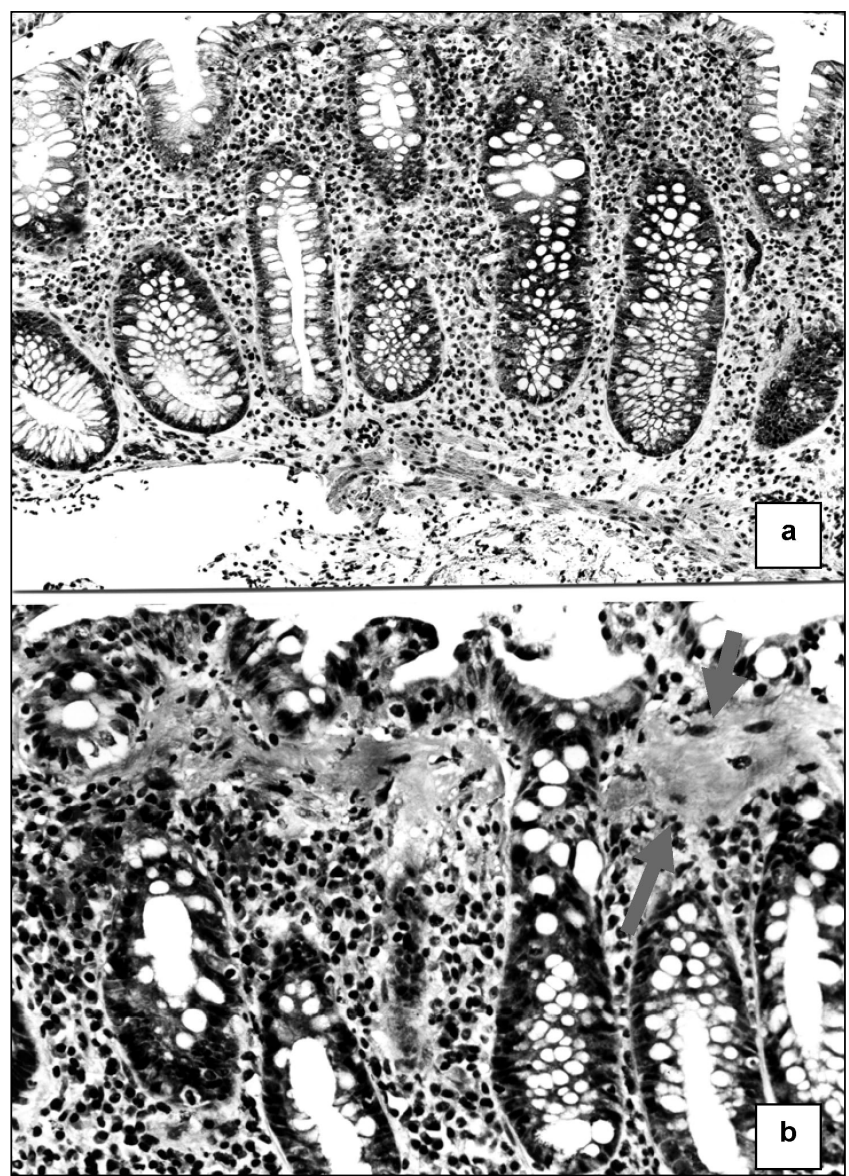

Figure 1) a Histological features of lymphocytic colitis. Note the increased infiltration of the lamina propria with inflammatory cells (which are predominantly lymphocytes). b Histological features of collagenous colitis. Note the thick collagen band underlying the epithelium (arrows), as well as increased infiltration of the lamina propria with inflammatory cells

The following features are required to make the histological diagnosis of $\mathrm{MC}(4,31,51,56)$ :

1. Diffuse thickening of a subepithelial collagen layer of more than $10 \mathrm{~mm}$ (range $7 \mu \mathrm{m}$ to $80 \mu \mathrm{m}$ ). Some studies suggest a cut-off limit of $15 \mu \mathrm{m}$ to $30 \mu \mathrm{m}$ (56).

2. Inflammation in the lamina propria consisting of mainly lymphocytes and plasma cells.

3. Epithelial lesions - flattening, detachment and intraepithelial lymphocytosis.

For LC, criteria 2 and 3 are enough to make the diagnosis when the collagen layer thickness is normal.

Importantly, MC may share some histological features with ulcerative colitis and Crohn's disease. In a study in which features of IBD were assessed in a group of patients with $\mathrm{MC}$, active crypt inflammation was seen in 24 of 79 CC patients (30\%) and 27 of $71 \mathrm{LC}$ patients (38\%), surface ulceration was not seen in any of the LC biopsies but was present in two of 79 CC patients (2.5\%). Paneth cell metaplasia was found in $44 \%$ of CC patients and $14 \%$ of those with LC. Distortion of crypt architecture was noted in $7.6 \%$ of patients with CC and $4.2 \%$ of patients with LC (57).
TABLE 2

Therapeutic options in microscopic colitis

\begin{tabular}{|c|c|c|c|}
\hline Agent & Dose/day & $\begin{array}{c}\text { Clinical } \\
\text { response (\%) }\end{array}$ & Reference \\
\hline Loperamide & 2 to $16 \mathrm{mg}$ & $71(n=69)$ & 15 \\
\hline \multirow[t]{4}{*}{ Budesonide } & $9 \mathrm{mg}$ & $100(n=2)$ & 15 \\
\hline & & $62(n=13)$ & 66 \\
\hline & & $100(n=7)$ & 67 \\
\hline & & $86.9(n=26)$ & 68 \\
\hline Bismuth subsalicylate & 2 to 3 tablets tid & $91(n=12)$ & 69 \\
\hline \multirow[t]{2}{*}{ Sulfasalazine } & 2 to $4 \mathrm{~g}$ & $59(n=108)$ & 15 \\
\hline & & $66(n=50)$ & 59 \\
\hline \multirow[t]{2}{*}{ Mesalamine } & 2 to $4 \mathrm{~g}$ & $45(n=31)$ & 15 \\
\hline & & $92(n=13)$ & 59 \\
\hline \multirow[t]{3}{*}{ Bile acid binding agents } & 4 to $20 \mathrm{~g}$ & $59(n=44)$ & 15 \\
\hline & & $33(n=6)$ & 59 \\
\hline & & $78(n=27)$ & \\
\hline \multirow[t]{2}{*}{ Prednisone } & 10 to $50 \mathrm{mg}$ & $82(n=39)$ & 15 \\
\hline & & $84(n=31)$ & 59 \\
\hline Azathioprine & 2 to $2.5 \mathrm{mg} / \mathrm{kg}$ & $87(n=8)$ & 70 \\
\hline Methotrexate & Not established & Case reports & 71,72 \\
\hline \multirow[t]{2}{*}{ Metronidazole } & $500 \mathrm{mg}$ tid & $55(n=44)$ & 15 \\
\hline & & $36(n=11)$ & 59 \\
\hline Erythromycin & $500 \mathrm{mg}$ bid & $67(n=15)$ & 15 \\
\hline Octreotide & Not established & Case report & 65 \\
\hline
\end{tabular}

The thickness of the collagen band in patients with CC appears to be greatest in the transverse (median $46.8 \mu \mathrm{m}$ ) and descending (median $49.2 \mu \mathrm{m}$ ) colon and less in the rectosigmoid (median $33.6 \mu \mathrm{m}$ ) and right (median $35.4 \mu \mathrm{m}$ ) colon (56). Because the distribution of MC is often patchy, the diagnosis can be missed with limited biopsies. In a study of 17 patients with known CC, complete colonoscopies were performed with segmental sampling (58). Rectal biopsies were normal in $73 \%$; the correct diagnosis was made in $82 \%$ that had biopsies from the left colon, suggesting that a thorough sigmoidoscopy could pick up the majority of cases (58). Other studies suggest that sigmoid biopsies miss only a small number of patients, while some studies claim that rectosigmoid biopsies can miss up to $40 \%$ of those with $\mathrm{MC}(59,60)$. A more recent study reported that the diagnostic yield was highest from biopsies of the transverse colon (83\%) and right colon (70\%) and lowest from the rectosigmoid colon (66\%) (56). In one large study, normal rectal biopsies were found in $43 \%$ of patients with CC and $8 \%$ of patients with LC (8). Thus, a sigmoidoscopic examination with biopsies of the left colon will pick up most cases of $\mathrm{MC}$ but a colonoscopy is required if the biopsies from the sigmoidoscopic examination are normal. Because LC and $\mathrm{CC}$ are relatively newly recognized entities and the histological changes can be subtle, the authors recommend that the biopsies be reviewed by a pathologist with a special interest in gastroenterology. In the last twelve months, the authors have made the diagnosis of $\mathrm{MC}$ in three patients with reportedly normal colonic biopsies by simply having the biopsies reviewed by a pathologist with a special interest in gastrointestinal pathology. All three patients have responded well to medical therapy.

Interestingly, a recent study showed that patients with LC or CC (without the diagnosis of celiac disease) had increased IELs in the terminal ileum compared with control patients 


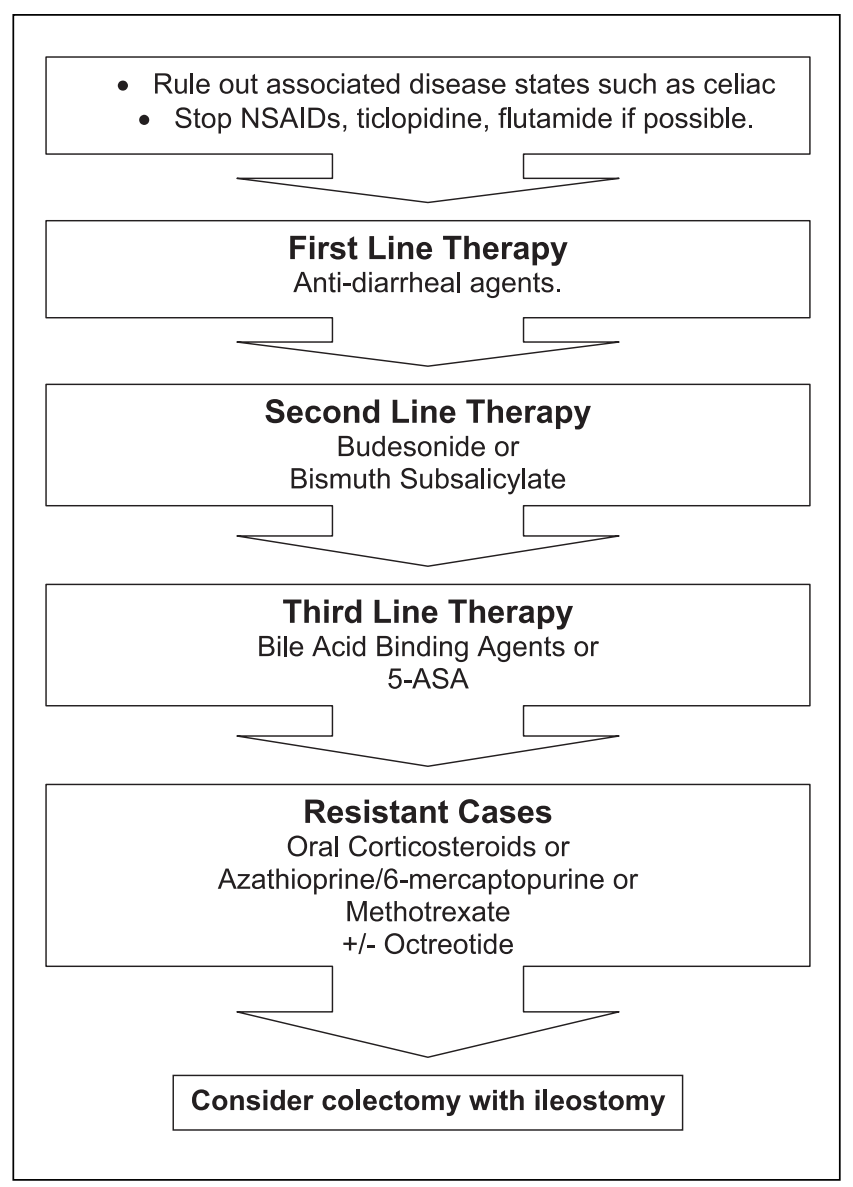

Figure 2) Suggested treatment algorithm for patients with microscopic colitis. ASA Acetylsalicylic acid; NSAID Nonsteroidal anti-inflammatory drug

and those with ulcerative colitis or colonic Crohn's disease (61). Remarkably, it was found that the presence of more than five IELs per 100 epithelial cells in terminal ileal biopsies was highly specific for LC and CC with a specificity of $98 \%$ for both LC and CC and a sensitivity of $73 \%$ for LC and $56 \%$ for CC (61).

\section{NATURAL HISTORY}

The natural history of MC is not clear. The mean duration of symptoms before diagnosis in one study (14) was two months for LC and four months for CC but these figures vary greatly. The clinical course is variable. Generally, symptoms are mild and spontaneous remissions can occur. One group reported that $84 \%$ of LC and $74 \%$ of CC patients had resolution or significant improvement (14). In a long term follow-up study, Bonner et al (14) reported that $81 \%$ reported improvement on 5 -acetylsalicylic acid (ASA) products and 100\% improved on oral corticosteroids. At 23 months, 86\% had improvement in their diarrhea with only $32 \%$ requiring routine medications, and by 47 months, only $29 \%$ of patients required routine medications (14). One study that followed patients for a mean of 3.5 years found that patients fell into two definable groups: those that were in complete remission (induced by drugs, removal of NSAIDs or spontaneously), which made up $63 \%$ of patients, and those with either ongoing or intermittent symptoms requiring at least intermittent therapy (37\%) (48). They noted no significant differences between the two groups with regard to age, sex, associated diseases and use of medications. Furthermore, there were no significant differences in collagen band thickness, epithelial damage or inflammation between the two groups (48).

Cancer risk has been assessed in 117 patients diagnosed with $\mathrm{CC}$ and followed for a mean of 7.0 years (range two to 12 years), during which time no patients developed colorectal cancer but an increased relative risk of lung cancer in women with CC was noted (62). The overall RR of malignancy and overall mortality was no different than that of the general population (62). With the increased RR of lung cancer in CC, the association between smoking and CC merits further study. The only study that the authors were aware of that assessed smoking in $\mathrm{MC}$ found that those with $\mathrm{CC}$ were more likely to be smokers than those with LC (25\% versus $14 \%$, respectively) (14).

\section{General approach}

\section{TREATMENT}

Numerous agents have been used in the treatment of MC from no therapy to high dose immune modulatory therapy. Unfortunately, most treatment approaches are based on very little significant clinical data. Thus, most physicians have adopted treating the individual patient in a stepwise approach, paying close attention to the potential side effect profile of the agents since MC usually has a benign course $(5,59)$. Several recent studies have reported on the medical management of MC (Table 2). Hence, we have incorporated these and previous studies and present a stepwise approach that is based on the available literature and the strength of existing evidence. The evidence was graded as levels 1 to 3 according to the Canadian Task Force on preventive health care (Table 2, Figure 2).

The initial approach should be to determine the patient's volume status and general medical condition. Volume repletion and corrections of possible aggravating factors (including caffeine, dairy products and dietary supplements) should be the initial step in management. Medications that may aggravate symptoms or even contribute in pathogenesis, such as NSAIDs and other agents such as ticlopidine and flutamide that have also been associated with MC, should be stopped if possible. A strong association has been suggested by some studies between MC and NSAIDs $(14,15,45-48)$. Other studies do not support the association of NSAIDs with MC $(13,63)$. Given the possible exacerbating effect of NSAIDs on other forms of IBD, and the studies suggesting a beneficial effect of stopping NSAIDs, it seems reasonable to suggest stopping NSAIDs, if possible, in MC patients (level 3 evidence).

First-line therapy

Antidiarrheals: Nonspecific antidiarrheal therapy has been commonly used in the management of $\mathrm{MC}$ yet no published prospective or randomized studies were identified. Results of the two largest retrospective studies are included in Table 2. Due to the relative safety of these agents and the possibility of spontaneous remission, many suggest that these agents should be the first-line therapy for MC $(15,59)$ (level 2 evidence). Case reports suggest that octreotide may be of benefit in controlling diarrhea in severe refractory cases $(64,65)$. Anecdotally, those with moderate to severe diarrhea and/or associated significant abdominal pain often fail to respond to antidiarrheal therapy alone. 


\section{Second-line therapy}

Budesonide: Budesonide is the most thoroughly studied agent in the treatment of MC. A recent randomized controlled trail of budesonide ( $9 \mathrm{mg}$ daily) compared with placebo, eight of 13 patients who completed the trial (on an intention-to-treat basis) had a clinical response compared with three of 14 patients in the placebo group (66). Histologically, there was no reduction in the thickness of the collagen layer but there was a significant reduction in inflammation (66). A previous open-labelled pilot study from Germany reported a significant clinical and histological response to budesonide in seven patients with CC (67). A randomized, double-blind, placebocontrolled multicentre trial was published in October 2002 by Miehlke et al (68). Fifty-one patients with CC were randomly assigned to receive either budesonide ( $9 \mathrm{mg} /$ day) or placebo for six weeks. The clinical remission in the budesonide group was $86.9 \%$ compared with $13.6 \%$ in the placebo group. Histological improvement was seen in $60.9 \%$ in the budesonide group compared with $4.5 \%$ in the placebo group. No significant changes in collagen band thickness were noted, but that result was not unexpected in view of the relatively short duration of treatment (68). The results of these three studies are very encouraging and, thus, we recommend budesonide therapy in patients who do not respond to antidiarrheal therapy (level 1 evidence) (Table 2).

Bismuth subsalicylate: There is only one published study assessing the use of bismuth subsalicylate in MC. Fine and Lee (69) performed a prospective open-labelled study in which 13 patients with $\mathrm{MC}$ (seven with $\mathrm{CC}$ ) were treated with eight chewable $262 \mathrm{mg}$ tablets per day for eight weeks. Remarkably, 11 of 12 patients who completed the trial had resolution of their diarrhea (69). There was histological improvement noted in nine of 12 patients. After a follow-up period of seven to 28 months, nine patients remained well and two required retreatment. Anecdotally, others have not had the same success rate with this therapy and many patients do not tolerate the eight tablets of bismuth subsalicylate per day. We recommend bismuth subsalicylate as second-line therapy and generally use it in those with more mild disease (level 2 evidence). We have also used it with success in patients that have required budesonide that have a mild flare after stopping the budesonide.

\section{Third-line therapy}

Bile acid binding agents: Use of agents that bind bile acids was reviewed in the pathogenesis section of the present paper. In short, a recent study by Ung et al (50) found that 44\% of patients with $\mathrm{CC}$ had abnormal bile acid absorption and that open-labelled cholestyramine (4 g per day) or colestipol (5 g per day) resulted in a rapid, marked or complete improvement in $78 \%$ of patients and in $92 \%$ of the patients with bile acid malabsorption (50). Bohr et al (15) reported a 59\% response

\section{REFERENCES}

1. Freeman HJ, Weinstein WM, Shnitka TK, Wensel RH, Sartor VE. Watery diarrhea syndrome associated with a lesion of the colonic basement membrane-lamina propria interface. Ann R Coll Physicians Surg Can 1976;9(45).

2. Lindstrom CG. 'Collagenous colitis' with watery diarrhoea - A new entity? Pathol Eur 1976;11:87-9.

3. Read NW, Krejs GJ, Read MG, Santa Ana CA, Morawski SG, Fordtran JS. Chronic diarrhea of unknown origin. Gastroenterology 1980;78:264-71.

4. Lazenby AJ, Yardley JH, Giardiello FM, Jessurun J, Bayless TM. Lymphocytic ("microscopic") colitis: A comparative histopathologic rate to cholestyramine. Thus, the use of bile acid binding agents is suggested especially in those with known bile acid malabsorption and in those who developed $\mathrm{MC}$ following cholecystectomy (level 2) (Table 2).

5-ASA: There are no prospective or randomized studies on the use of mesalamine or sulfasalazine in the treatment of MC. The results of the two large retrospective studies are summarized in Table 1. Anecdotally, most individuals are not impressed by the results of these agents; however, sporadically, some patients seem to respond well to 5-ASA. Thus, because these agents are generally less expensive than budesonide, have few side effects and can be effective, we still recommend these agents in the management of MC, but they should ideally be used after the patient has failed more potent agents such as budesonide or bismuth (level 3 evidence) (Table 2).

\section{Resistant cases}

Again, no prospective or randomized studies have been done on the use of oral corticosteroids or other oral immune modulatory medications in MC. The results of the two largest retrospective reports are summarized in Table 2 (level 2). It is suggested that patients refractory to the above therapies should be treated with a short course of oral steroids. Most patients will have a positive response to therapy but the relapse rate is high. Pardi et al (70) reported retrospective analyses of all patients treated at the Mayo clinic for microscopic colitis with azathioprine and 6-mercaptopurine. All patients were either refractory to steroids or dependent on steroids. A total of nine patients with $\mathrm{MC}$ were identified (six with $\mathrm{CC}$ ). Four of eight patients who were on steroids had resolution of diarrhea and withdrawal of steroids with the introduction of either azathioprine or 6-mercaptopurine (70). The other patients were able to taper or discontinue steroids but had continued mild diarrhea. Severe diarrhea persisted in one patient requiring an ileostomy (70). In case reports, methotrexate has also been shown to be of benefit in a small number of patients $(15,71,72)$. Patients who are refractory to oral steroids or relapse after discontinuation of oral steroids should likely be tried on immune modulatory therapy such as azathioprine (level 2 evidence) (Table 2).

\section{CONCLUSION}

Microscopic colitis is a relatively common cause of chronic diarrhea in middle aged and elderly patients, especially in those who have endoscopically normal appearing colonic mucosa. The standard approach is to first rule out other common causes of chronic diarrhea. Once the diagnosis of $\mathrm{MC}$ is confirmed by colonic biopsy, the first intervention should involve terminating the use of agents such as NSAIDs that may be involved in the pathogenesis of MC. A stepwise approach to medical therapy should then be instituted.

study with particular reference to collagenous colitis. Hum Pathol 1989;20:18-28.

5. Pardi DS, Smyrk TC, Tremaine WJ, Sandborn WJ. Microscopic colitis: A review. Am J Gastroenterol 2002;97:794-802.

6. Bohr J, Olesen M, Tysk C, Jarnerot G. Collagenous and lymphocytic colitis: A clinical and histopathological review. Can J Gastroenterol 2000;14:943-7.

7. Sylwestrowicz T, Kelly JK, Hwang WS, Shaffer EA. Collagenous colitis and microscopic colitis: The watery diarrhea-colitis syndrome. Am J Gastroenterol 1989;84:763-8.

8. Fernandez-Banares F, Salas A, Forne M, Esteve M, Espinos J, 
Viver JM. Incidence of collagenous and lymphocytic colitis: A 5-year population-based study. Am J Gastroenterol 1999;94:418-23.

9. Bohr J, Tysk C, Eriksson S, Jarnerot G. Collagenous colitis in Orebro, Sweden, an epidemiological study 1984-1993. Gut 1995;37:394-7.

10. Agnarsdottir M, Gunnlaugsson $\mathrm{O}$, Orvar KB, et al. Collagenous and lymphocytic colitis in Iceland. Dig Dis Sci 2002;47:1122-8.

11. Cross A, Treanor D, Keegan D, Sheahan K, Mulcathy H, O'Donoghue D. Microscopic colitis - Increased incidence or increased recognition? Gastroenterology 2002;122:A-602. Abst

12. Erdem L, Yildirim S, Yilmaz B, et al. The rate of microscopic colitis in patients with chronic diarrhea with unknown etiology. Gastroenterology 2002;122:W1608.

13. Abdo A, Raboud J, Freeman HJ, et al. Clinical and histological predictors of response to medical therapy in collagenous colitis. Am J Gastroenterol 2002;97:1164-8.

14. Bonner GF, Petras RE, Cheong DM, Grewal ID, Breno S, Ruderman WB. Short- and long-term follow-up of treatment for lymphocytic and collagenous colitis. Inflamm Bowel Dis 2000;6:85-91.

15. Bohr J, Tysk C, Eriksson S, Abrahamsson H, Jarnerot G. Collagenous colitis: A retrospective study of clinical presentation and treatment in 163 patients. Gut 1996;39:846-51.

16. Gremse DA, Boudreaux CW, Manci EA. Collagenous colitis in children. Gastroenterology 1993;104:906-9.

17. Deslandres C, Moussavou-Kombilia JB, Russo P, Seidman EG. Steroid-resistant lymphocytic enterocolitis and bronchitis responsive to 6-mercaptopurine in an adolescent. J Pediatr Gastroenterol Nutr 1997;25:341-6.

18. Mahajan L, Wyllie R, Goldblum J. Lymphocytic colitis in a pediatric patient: A possible adverse reaction to carbamazepine. Am J Gastroenterol 1997;92:2126-7.

19. Torrente F, Ashwood P, Day R, et al. Small intestinal enteropathy with epithelial IgG and complement deposition in children with regressive autism. Mol Psychiatry 2002;7:375-82.

20. Furlano RI, Anthony A, Day R, et al. Colonic CD8 and gamma delta T-cell infiltration with epithelial damage in children with autism. J Pediatr 2001;138:366-72.

21. Breen EG, Farren C, Connolly CE, McCarthy CF. Collagenous colitis and coeliac disease. Gut 1987;28:364.

22. McCashland TM, Donovan JP, Strobach RS, Linder J, Quigley EM. Collagenous enterocolitis: A manifestation of gluten-sensitive enteropathy. J Clin Gastroenterol 1992;15:45-51.

23. Jean R, Durand JM, Cretel E, et al. [Lymphocytic colitis and Gougerot-Sjogren syndrome. Report of two cases]. Rev Med Interne 1999;20:923-5.

24. Kandemir O, Utas C, Gonen O, et al. Colonic subepithelial collagenous thickening in diabetic patients. Dis Colon Rectum 1995;38:1097-100.

25. Taccari E, Spada S, Giuliani A, et al. Co-occurrence of psoriatic arthritis with collagenous colitis: Clinicopathologic findings of a case. Clin Rheumatol 2002;21:335-8.

26. Cindoruk M, Tuncer C, Dursun A, et al. Increased colonic intraepithelial lymphocytes in patients with Hashimoto's thyroiditis. J Clin Gastroenterol 2002;34:237-9.

27. Pariente EA, Chaumette MT, Maitre F, Delchier JC, Soule JC, Bader JP. [Collagenous colitis, IgA deficiency, Basedow's disease and atrophic gastritis]. Gastroenterol Clin Biol 1985;9:738-41.

28. Freeman HJ. Perinuclear antineutrophil cytoplasmic antibodies in collagenous or lymphocytic colitis with or without celiac disease. Can J Gastroenterol 1997;11:417-20.

29. Bohr J, Tysk C, Yang P, Danielsson D, Jarnerot G. Autoantibodies and immunoglobulins in collagenous colitis. Gut 1996;39:73-6.

30. Greenson JK, Giardiello FM, Lazenby AJ, Pena SA, Bayless TM, Yardley JH. Antireticulin antibodies in collagenous and lymphocytic (microscopic) colitis. Mod Pathol 1990;3:259-60.

31. Jarnerot G, Tysk C, Bohr J, Eriksson S. Collagenous colitis and fecal stream diversion. Gastroenterology 1995;109:449-55.

32. Mosnier JF, Larvol L, Barge J, et al. Lymphocytic and collagenous colitis: An immunohistochemical study. Am J Gastroenterol 1996;91:709-13.

33. Giardiello FM, Lazenby AJ, Yardley JH, et al. Increased HLA A1 and diminished HLA A3 in lymphocytic colitis compared to controls and patients with collagenous colitis. Dig Dis Sci 1992;37:496-9.

34. Fine KD, Do K, Schulte K, et al. High prevalence of celiac sprue-like HLA-DQ genes and enteropathy in patients with the microscopic colitis syndrome. Am J Gastroenterol 2000;95:1974-82.
35. Abdo AA, Zetler PJ, Halparin LS. Familial microscopic colitis. Can J Gastroenterol 2001;15:341-3.

36. van Tilburg AJ, Lam HG, Seldenrijk CA, et al. Familial occurrence of collagenous colitis. A report of two families. J Clin Gastroenterol 1990;12:279-85.

37. Freeman HJ. Familial occurrence of lymphocytic colitis. Can J Gastroenterol 2001;15:757-60

38. Baum CA, Bhatia P, Miner PB Jr. Increased colonic mucosal mast cells associated with severe watery diarrhea and microscopic colitis. Dig Dis Sci 1989;34:1462-5.

39. Levy AM, Yamazaki K, Van Keulen VP, et al. Increased eosinophil infiltration and degranulation in colonic tissue from patients with collagenous colitis. Am J Gastroenterol 2001;96:1522-8.

40. Stahle-Backdahl M, Maim J, Veress B, Benoni C, Bruce K, Egesten A. Increased presence of eosinophilic granulocytes expressing transforming growth factor-beta1 in collagenous colitis. Scand J Gastroenterol 2000;35:742-6.

41. Perner A, Andresen L, Normark M, et al. Expression of nitric oxide synthases and effects of L-arginine and L-NMMA on nitric oxide production and fluid transport in collagenous colitis. Gut 2001;49:387-94.

42. Lundberg JO, Herulf M, Olesen M, et al. Increased nitric oxide production in collagenous and lymphocytic colitis. Eur J Clin Invest 1997;27:869-71.

43. Burgel N, Bojarski C, Mankertz J, Zeitz M, Fromm M, Schulzke JD. Mechanisms of diarrhea in collagenous colitis. Gastroenterology 2002;123:433-43.

44. Rask-Madsen J, Grove O, Hansen MG, Bukhave K, Scient C, Henrik-Nielsen R. Colonic transport of water and electrolytes in a patient with secretory diarrhea due to collagenous colitis. Dig Dis Sci 1983;28:1141-6.

45. Riddell RH, Tanaka M, Mazzoleni G. Non-steroidal antiinflammatory drugs as a possible cause of collagenous colitis: A casecontrol study. Gut 1992;33:683-6.

46. Miquel Plaza J, Lopez SanRoman A, del Pozo D, et al. [Evolution and treatment response in microscopic colitis]. Gastroenterol Hepatol 2001;24:433-9.

47. Giardiello FM, Hansen FC III, Lazenby AJ, et al. Collagenous colitis in setting of nonsteroidal antiinflammatory drugs and antibiotics. Dig Dis Sci 1990;35:257-60

48. Goff JS, Barnett JL, Pelke T, Appelman HD. Collagenous colitis: Histopathology and clinical course. Am J Gastroenterol 1997; $92: 57-60$

49. Gurbuz Y, Senturk O, Muezzinoglu B. Postcholecystectomy microscopic colitis: Is bile acid malabsorption a triggering factor? Am J Gastroenterol 2001;96:1655-6.

50. Ung KA, Gillberg R, Kilander A, Abrahamsson H. Role of bile acids and bile acid binding agents in patients with collagenous colitis. Gut 2000;46:170-5.

51. Giardiello FM, Bayless TM, Jessurun J, Hamilton SR, Yardley JH. Collagenous colitis: Physiologic and histopathologic studies in seven patients. Ann Intern Med 1987;106:46-9.

52. Fernandez-Banares F, Esteve M, Salas A, et al. Bile acid malabsorption in microscopic colitis and in previously unexplained functional chronic diarrhea. Dig Dis Sci 2001;46:2231-8.

53. Fine KD. The prevalence of occult gastrointestinal bleeding in celiac sprue. N Engl J Med 1996;334:1163-7.

54. Arora DS, Mahmood T, Wyatt JI. Lymphocytic venulitis: An unusual association with microscopic colitis. J Clin Pathol 1999;52:303-4.

55. Wang N, Dumot JA, Achkar E, Easley KA, Petras RE, Goldblum JR. Colonic epithelial lymphocytosis without a thickened subepithelial collagen table: A clinicopathologic study of 40 cases supporting a heterogeneous entity. Am J Surg Pathol 1999;23:1068-74.

56. Offner FA, Jao RV, Lewin KJ, Havelec L, Weinstein WM. Collagenous colitis: A study of the distribution of morphological abnormalities and their histological detection. Hum Pathol 1999;30:451-7.

57. Ayata G, Ithamukkala S, Sapp H, et al. Prevalence and significance of inflammatory bowel disease-like morphologic features in collagenous and lymphocytic colitis. Am J Surg Pathol 2002;26:1414-23.

58. Tanaka M, Mazzoleni G, Riddell RH. Distribution of collagenous colitis: Utility of flexible sigmoidoscopy. Gut 1992;33:65-70.

59. Zins BJ, Tremaine WJ, Carpenter HA. Collagenous colitis: Mucosal biopsies and association with fecal leukocytes. Mayo Clin Proc $1995 ; 70: 430-3$. 
60. Carpenter HA, Tremaine WJ, Batts KP, Czaja AJ. Sequential histologic evaluations in collagenous colitis. Correlations with disease behavior and sampling strategy. Dig Dis Sci 1992;37:1903-9.

61. Sapp H, Ithamukkala S, Brien TP, et al. The terminal ileum is affected in patients with lymphocytic or collagenous colitis. Am J Surg Pathol 2002;26:1484-92.

62. Chan JL, Tersmette AC, Offerhaus GJ, Gruber SB, Bayless TM, Giardiello FM. Cancer risk in collagenous colitis. Inflamm Bowel Dis 1999;5:40-3.

63. Veress B, Lofberg R, Bergman L. Microscopic colitis syndrome. Gut 1995;36:880-6.

64. Fisher NC, Tutt A, Sim E, Scarpello JH, Green JR. Collagenous colitis responsive to octreotide therapy. J Clin Gastroenterol 1996;23:300-1.

65. Marshall JK, Irvine EJ. Lymphocytic and collagenous colitis: Medical management. Curr Treat Options Gastroenterol 1999;2:127-33.

66. Baert F, Schmit A, D'Haens G, et al. Budesonide in collagenous colitis: A double-blind placebo-controlled trial with histologic follow-up. Gastroenterology 2002;122:20-5.
67. Tromm A, Griga T, Mollmann HW, May B, Muller KM, Fisseler-Eckhoff A. Budesonide for the treatment of collagenous colitis: First results of a pilot trial. Am J Gastroenterol 1999;94:1871-5.

68. Miehlke S, Heymer P, Bethke B, et al. Budesonide treatment for colagenous colitis: A randomized double-blind, placebo-controlled, multicenter trial. Gastroenterology 2002;123:978-84.

69. Fine KD, Lee EL. Efficacy of open-label bismuth subsalicylate for the treatment of microscopic colitis. Gastroenterology 1998; 114:29-36.

70. Pardi DS, Loftus EV Jr, Tremaine WJ, Sandborn WJ. Treatment of refractory microscopic colitis with azathioprine and 6-mercaptopurine. Gastroenterology 2001;120:1483-4.

71. Benucci M, Bardazzi G, Magaro L, Li Gobbi F, Mannoni A, Serni U. A case report of a man with rheumatoid factor positive rheumatoid arthritis associated with collagenous colitis. Clin Exp Rheumatol 2001;19:475.

72. Bhullar DS, Tymms KE, Hillman L, Jain S. Treatment of collagenous colitis with methotrexate. Aust N Z J Med 1996;26:114. 


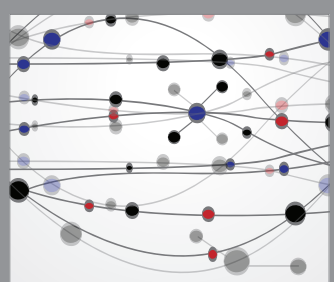

The Scientific World Journal
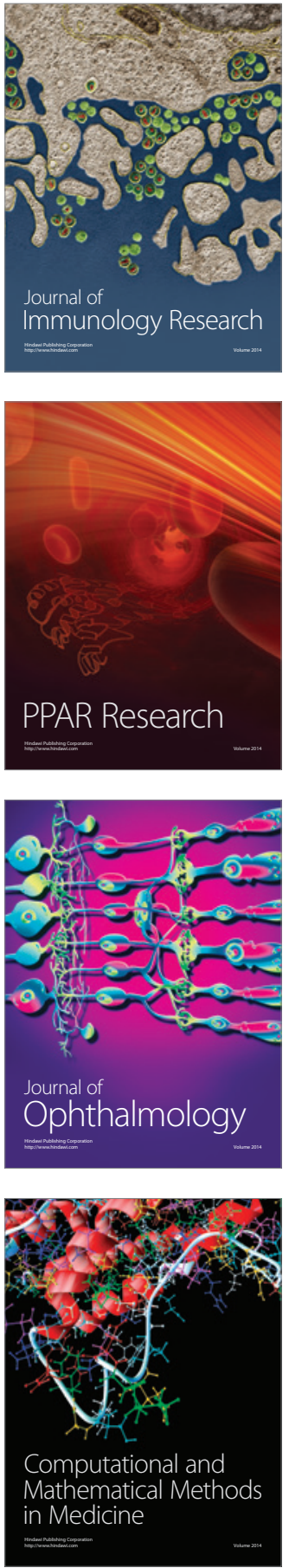

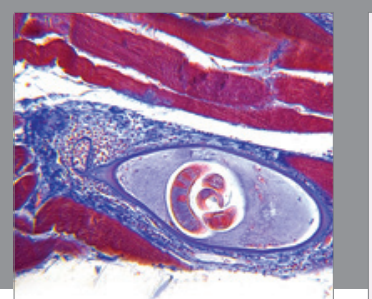

Gastroenterology Research and Practice

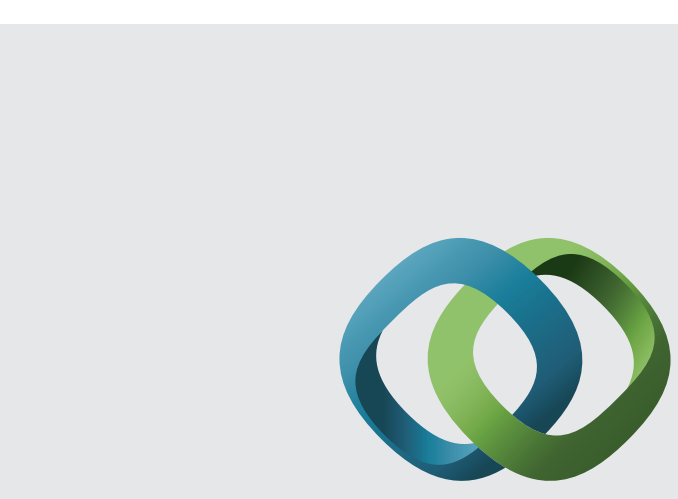

\section{Hindawi}

Submit your manuscripts at

http://www.hindawi.com
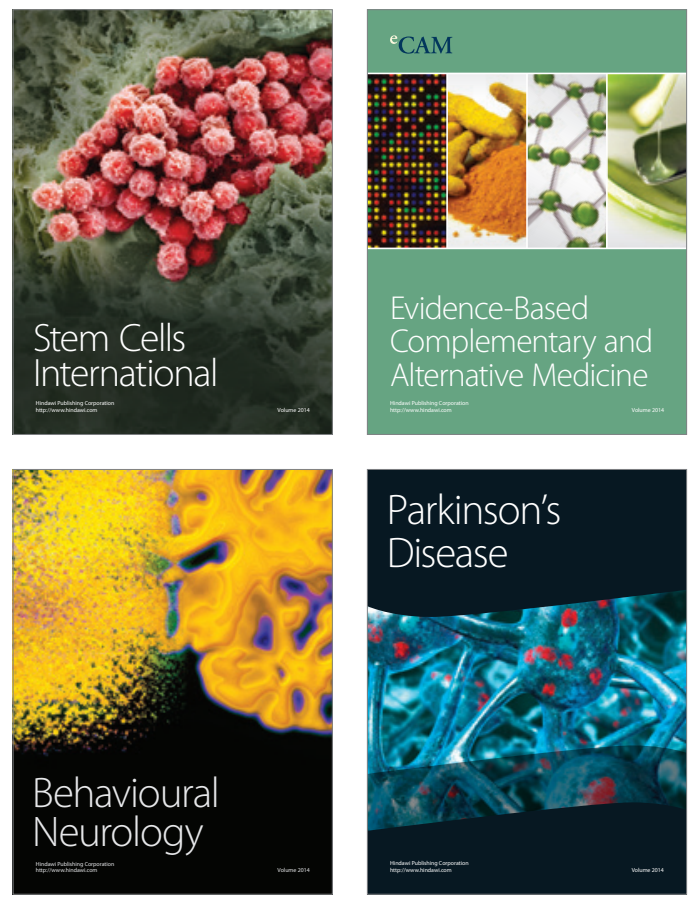
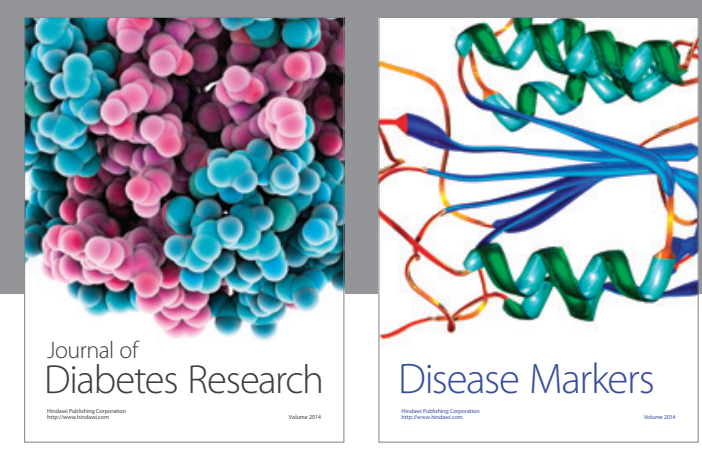

Disease Markers
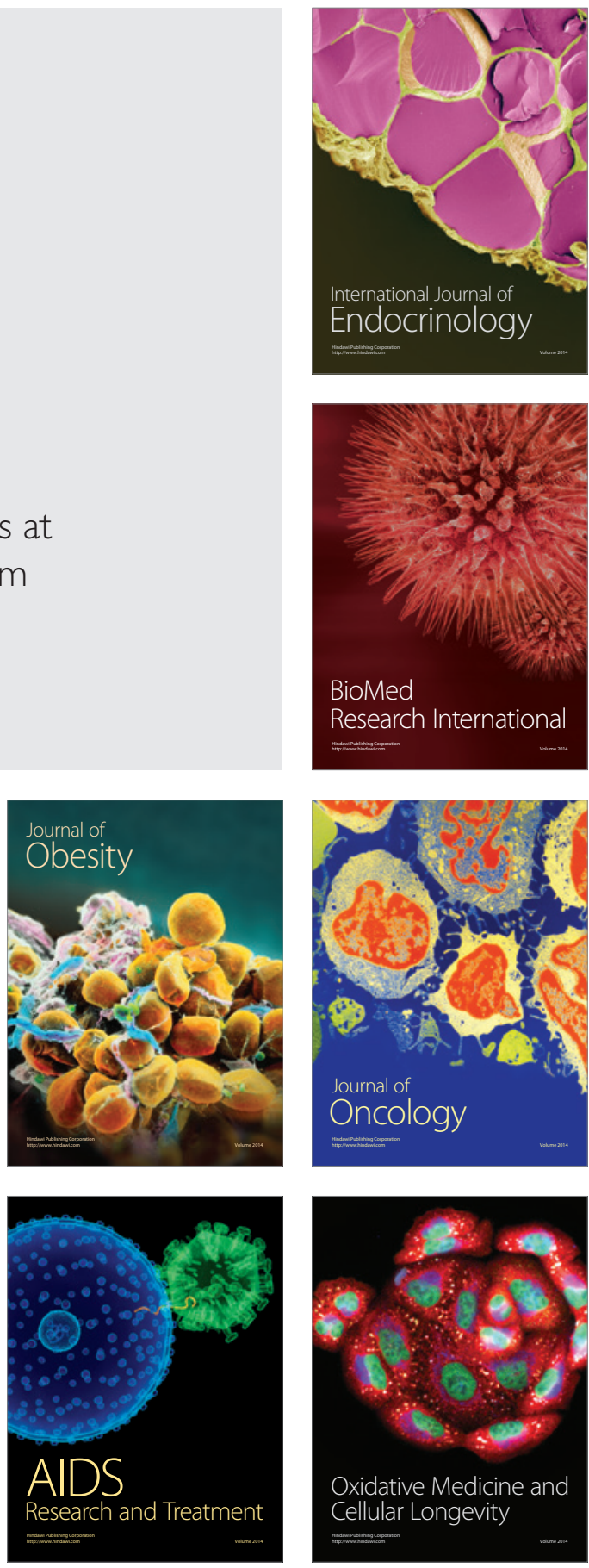